\title{
Inserción de los países de la Alianza del Pacífico en Asia-Pacífico: más allá de las relaciones comerciales
}

\author{
DANIEL ROJAS* \\ José Miguel TeráN**
}

\begin{abstract}
Artículo recibido: 19 de mayo de 2016
\end{abstract}
Artículo aceptado: 8 de marzo de 2017

Doi: http://dx.doi.org/10.12804/revistas.urosario.edu.co/desafios/a.4888

Para citar este artículo: Rojas, D., Terán, J. M. (2017). Inserción de los países de la Alianza del Pacífico en Asia-Pacífico: más allá de las relaciones comerciales. Desafíos, 29(2), 237-275. doi: http://dx.doi.org/10.12804/revistas.urosario.edu.co/desafios/a.4888

\section{Resumen}

El siglo XXI ha sido considerado como el siglo del Pacifico. La Alianza del Pacífico no es ajena a dicho fenómeno la cual, entre otros motivos, surgió para lograr una mejor inserción de sus países miembro en esta área y, más específicamente, en la parte asiática del Pacífico. Dicha inserción ha tendido a explicarse en términos de intercambios comerciales, los cuales se han incrementado en los últimos años y tienen una importancia central en las interrelaciones, pero no evidencian el amplio alcance que tienen las relaciones entre Chile, Colombia, México y Perú con Asia-Pacífico; además, la política exterior no se limita a la búsqueda de nuevos mercados y socios económicos. Este trabajo presenta una sistematización de tratados establecidos entre los países que son actualmente miembros de la Alianza del Pacífico con China, Corea

\footnotetext{
* Politólogo con énfasis en Relaciones Internacionales, Universidad Icesi. Estudiante Maestría en Ciencias Sociales, Flacso-México. Correo electrónico: daniel.rojas.lozano@, gmail.com. ORCID: http://orcid.org/0000-0002-8902-1224

** Abogado y politólogo con énfasis en Relaciones Internacionales, Universidad Icesi. Coordinador del Programa de Estudios de la Alianza del Pacífico, PEAP, de la misma Universidad. Correo electrónico: jmteran@icesi.edu.co. ORCID: http: orcid.org/0000-0002-9791-8963
} 
y Japón entre los años 1990 y 2016. A partir del análisis comparado del conjunto de tratados se observa que el tema de comercio tiene una participación muy baja en la totalidad de las relaciones que se consolidan a través de los tratados.

Palabras clave: Alianza del Pacífico, relaciones comerciales, tratados bilaterales, Asia-Pacífico

\title{
Beyond Trade Relations: Insertion of the Pacific Alliance Members into the Asia-Pacific Region
}

\begin{abstract}
The twentieth-first century has been deemed as the "Pacific century". The Pacific Alliance is not unrelated to this phenomenon and, among other reasons, is meant to serve for a better insertion of its member-states into the international arena, and more specifically, into the Asian side of the Pacific. This insertion tends to be explained in terms of trade, which has increased over the last years and plays a central role in the relations among member-states. However, trade alone does not cover the wide range of relations that Chile, Colombia, Mexico and Peru have with the Asia-Pacific region. In addition, their foreign policy is not limited to the search for new markets and economic partners. This article presents a systematization of the treaties signed among the current Pacific Alliance members and China, South Corea and Japan between 1990 and 2016. Based on a comparative analysis of the treaties, it is observed that trade has in fact a very low participation as part of the overall relations between the Pacific Alliance and the Asia-Pacific region.
\end{abstract}

Key words: Pacific Alliance, trade relations, bilateral treaties, Asia-Pacific region

\section{Inserção dos países da Aliança do Pacífico na Ásia-Pacífico: para além das relações comerciais}

\footnotetext{
Resumo

O século XXI tem sido considerado como século do Pacífico. A Aliança do Pacífico não é alheia a dito fenômeno e, entre outros motivos, surgiu para conseguir uma melhor inserção dos seus países membros nesta área, e mais especificamente,
} 
na parte asiática do Pacifico. Dita inserção tem tendido a explicar-se em termos de intercâmbios comerciais, os quais se têm incrementado nos últimos anos e têm uma importância central nas inter-relações, mas não evidenciam o amplo alcance que têm as elações entre o Chile, a Colômbia, o México e o Peru com a Ásia-Pacífico; além disso, a política exterior não se limita à busca de novos mercados e sócios económicos. Este trabalho apresenta uma sistematização de tratados estabelecidos entre os países atualmente membros da Aliança do Pacífico com a China, a Coreia e o Japão entre os anos 1990 e 2016. A partir da análise comparada do conjunto de tratados observa-se que o tema de comércio tem uma participação muito baixa na totalidade das relações que se consolidam através dos tratados.

Palavras-chave: Aliança do Pacífico, relações comerciais, tratados bilaterais, ásia-Pacifico

\section{Introducción}

El siglo XXI ha sido considerado como el siglo del Pacífico o The Pacific Age (Faust, 2004; Tricks, 2014) y se ha distinguido por un reordenamiento mundial que le ha dado mayor importancia al Pacífico global. Esta región es clave en el contexto actual y los miembros de la Alianza del Pacífico (AP) hacen parte de ella. Chile, México y Perú tienen consolidada una posición ventajosa en la misma, lo que se refleja en su participación en el Foro de Cooperación Económica Asia-Pacífico (APEC por sus siglas en inglés) y en el Acuerdo de Asociación Transpacífico (TPP por sus siglas en inglés).

Es necesario reconocer, como lo hiciese en su momento Hillary Clinton (2011), que el "futuro de la política se decidirá en Asia". La región de Asia-Pacífico se ha convertido en un factor clave de la política mundial. La región se extiende por dos océanos —el Pacífico y el Índico_- que están cada vez más vinculados. Desde 1990 cuenta con casi la mitad de la población mundial, incluye muchos de los motores principales de la economía global, así como los mayores emisores de gases de efecto invernadero. Además, es el hogar de importantes potencias emergentes (Clinton, 2011).

La Alianza del Pacífico no es ajena a dicho fenómeno y, entre otros motivos, surgió para lograr una mejor inserción de sus países miembro 
en esta área, más específicamente en la parte asiática del Pacífico (Alianza del Pacífico, 2011). Dicha inserción ha tendido a explicarse en términos de intercambios comerciales, los cuales, si bien se han incrementado en los últimos años y tienen una importancia central en las interrelaciones, no evidencian el amplio alcance que tienen las relaciones entre Chile, Colombia, México y Perú con Asia-Pacífico ${ }^{1}$.

En este sentido vale resaltar que, si bien dentro de los cuatro principales destinos de importaciones y exportaciones de los países AP se encuentra al menos uno de los tres principales países de Asia-Pacífico, su participación en el comercio exterior de los países AP varía significativamente ${ }^{2}$ y tiende a predominar China como principal socio comercial. Por ejemplo, según datos de la Organización Mundial del Comercio, en el año 2015 el principal destino de las exportaciones chilenas y peruanas fue China (26,3\% y 22,1 \%, respectivamente), mientras que en México y Colombia, China ocupo el cuarto lugar, pero la participación fue del 1,3\% y 6,3\% respectivamente. Dentro de los principales países de origen de las importaciones, China continúa siendo predominante con respecto a Corea y Japón, sin embargo su participación no se muestra tan dispar. Por ejemplo en Chile, en donde el principal país de origen de las importaciones fue China, las mismas tuvieron una participación del 23,5\%, mientras que en México, donde China ocupó el cuarto lugar, la participación del país asiático en el total de importaciones fue del 17,7\%.

El anterior escenario de comercio internacional sugiere por lo menos dos cuestiones: primero, en términos meramente comerciales, no todos los países AP muestran un significativo nivel de inserción en Asia-Pacífico. Segundo, dentro de los tres principales países asiáticos, China tiene un claro predominio en la relación comercial con los países AP, por lo que dicha dimensión comercial no da cuenta

\footnotetext{
1 Cuando se haga referencia a la región Asia-Pacífico se la entenderá en el sentido que expone Eric Tremolada (2014), es decir, como la región a la que pretenden insertarse los países miembros de la AP y que se ubica en la zona oriental de Asia: China, Corea y Japón, países que además son economías líderes de Asia.

2 Ver OMC, perfiles comerciales.
} 
del grado de relación e inserción de los países AP con Japón y Corea. En este sentido, es preciso mencionar a manera de ejemplo que en el año 2016 el presidente mexicano Peña Nieto recibió a su homóloga coreana en el marco del $54^{\circ}$ aniversario del inicio de las relaciones diplomáticas entre ambos países; durante la visita se suscribieron 17 acuerdos y memorandos de entendimiento en temas de tecnología e innovación, turismo, entre otros (Excelsior, 2016). Ese mismo año, en el marco de la visita del primer mandatario chino a la región, ministros de Perú y del país asiático firmaron convenios de cooperación en materia medioambiental (La República, 2016), mientras que en Chile se firmaron 12 acuerdos con el presidente chino en temas de educación y ciencia, entre otros (Diario Financiero, 2016).

Analizar el grado de inserción de los países AP en Asia-Pacífico requiere entonces de una herramienta analítica que no se enmarque únicamente en dinámicas comerciales, pues estas no constituyen una explicación exhaustiva de la inserción. Además, dado el creciente interés académico y político en este proceso de integración ${ }^{3}$, es importante y pertinente preguntarse qué aspectos se han dinamizado en la política exterior de los países AP con los de Asia-Pacífico, particularmente entre los años 1990 y 2016.

Lo anterior es interesante en la medida en que la acción de la política exterior no se limita a la búsqueda de nuevos mercados y socios económicos; incluye también la suscripción de acuerdos y tratados (Forero, 2015) que a su vez son un indicador razonablemente fiable de los intereses de política exterior (Milanese \& Fernández, 2012; Terán, 2016). De igual forma, los intereses de los Estados se perfeccionan cada vez más en tratados internacionales, abarcando una amplia gama de temas, especialmente desde la década de 1990 (Slaughter, Tulumello y Wood, 1998). En coherencia con lo anterior, esas relaciones amplias que establecen los miembros de la AP con los países

\footnotetext{
3 Ver, por ejemplo, las ediciones dedicadas a la Alianza del Pacífico de las revistas Estudios Gerenciales 32 (141) y la Revista Mexicana de Política Exterior (106) en el año 2016 y la revista Desafíos 29 (1) en el 2017.
} 
de Asia-Pacífico, y que incluyen también las comerciales, se cristalizan en tratados internacionales de diversos temas de interés estatal.

\section{Objetivo y metodología de investigación}

Este trabajo, de carácter descriptivo, presenta una caracterización de los diferentes tratados establecidos entre los países que son actualmente miembros de la Alianza del Pacífico con China, Corea y Japón entre los años 1990 y 2016. La temporalidad seleccionada responde a varias particularidades que surgieron en la década de 1990 y que se han profundizado hasta la actualidad, especialmente en los países de la AP. Entre estas, se destacan el hecho de que los países de América Latina realizaron procesos de apertura y liberalización económica; se dieron reformas constitucionales que se enmarcaron en los preceptos liberales del periodo; así mismo se profundizó el interés en Asia, sobre todo desde el punto de vista económico y comercial (Coutin y Terán, 2016). En relación con el último punto, fue la década donde Chile, México y Perú lograron su membresía en APEC, en los años 1994, 1993 y 1998 respectivamente, reforzando sus relaciones con la región y donde Colombia quedó relegada por la moratoria que estableció el mecanismo. Por último, es necesario recalcar que este periodo se caracteriza por la proliferación de acuerdos internacionales en lo que se denomina en la literatura como el spaguetti bowl (Bhagwati, 1994).

Por otra parte, el levantamiento de información se realizó a través de la sistematización y depuración de las bases de tratados virtuales y de acceso público ${ }^{4}$ de las cancillerías de cada país miembro de la AP y de un levantamiento en campo de algunos tratados que no se encontraban sistematizados, para el caso del Perú. Para que las bases de datos fueran comparables se integraron y homogenizaron las categorías de análisis y se privilegió el análisis cuantitativo.

\footnotetext{
4 Estas pueden ser consultadas en: Chile: https://www.leychile.cl/Consulta/buscador_tratados; Colombia: http://apw.cancilleria.gov.co/Tratados/SitePages/Menu.aspx; México: http://tratados.sre.gob.mx/ y Perú: https://apps.rree.gob.pe/portal/webtratados.nsf
} 
Vale anotar que el presente texto se centra en el estudio de los acuerdos bilaterales en su totalidad, por considerarlos indicadores fiables de las tendencias de las relaciones entre los países bajo estudio. En ese sentido, el texto presenta un análisis sistémico y macro en la medida en que interesa analizar los tratados en su generalidad sin dar preponderancia a su temática, temporalidad, objetivo o cualquier otro criterio por el cual se ponderen o jerarquicen los mismos. Lo anterior permite contrastar las relaciones que cada uno de los miembros de la Alianza tiene con las tres principales economías de Asia, lo que posibilita identificar el estado de las relaciones con las que cada uno de los países latinoamericanos llega a conformar el proyecto de integración.

A partir de esta consolidación de tratados se buscará determinar si la inserción de los países de la Alianza del Pacífico en Asia-Pacífico es reciente o no; además, se indagará por el carácter de dicha inserción, clasificando los tratados por temas, de manera que sea posible comprobar si el acercamiento entre estas dos regiones ha sido meramente económico —énfasis de gran parte de la literatura existente- o si, por el contrario, se han abarcado diferentes dimensiones. Lo último es de vital importancia debido a las características endógenas de la AP, las cuales, como se argumentará más adelante, justifican el análisis de los tratados bilaterales.

Este trabajo se divide en cuatro secciones adicionales a esta introducción y a la presentación del objetivo y la metodología. En la tercera sección se presenta una revisión de la literatura referente a la inserción de Chile, Colombia, México y Perú en Asia-Pacífico, resaltando la importancia central que se le ha dado a los aspectos económicos y comerciales. En la cuarta parte se expondrán algunos elementos conceptuales que permitirán comprender el valor que tienen los tratados dentro de los sistemas jurídicos de cada país y su relevancia en relación con la política exterior. Posteriormente, se presentarán los tratados consolidados y se analizará el proceso de inserción mediante su clasificación. Por último, se discutirán los principales hallazgos y se dejarán planteadas algunas ideas para futuras investigaciones. 


\section{Revisión de literatura}

Las relaciones entre Asia y América Latina, durante las últimas décadas, han estado marcadas por un antes y un después, definido por el final de la Guerra Fría. Durante este periodo, los vínculos entre ambas regiones se limitaban a cuestiones ideológicas y diplomáticas, sin embargo, una vez finalizado este periodo, aquellos tomaron un nuevo rumbo (Ding, 2008). Los temas diplomáticos abordados años atrás cedieron su lugar a cuestiones económicas, las cuales han predominado en la agenda (Faust, 2004) tanto de los países, como de los académicos, quienes se han enfocado en el análisis de intercambios comerciales para evidenciar el nivel de inserción, particularmente de los países latinoamericanos.

En este sentido, los diferentes estudios sobre la inserción de Chile, Colombia, México y Perú en Asia-Pacífico han tomado el nivel de importaciones y exportaciones como uno de los factores que explican dicha inserción (Gago, 2001; Sanhueza y Soto, 2009; Torres, 2013, entre otros). Adicionalmente, algunas investigaciones han hecho referencia a la participación de líderes latinoamericanos en foros multilaterales como el APEC para resaltar el proceso de inserción (Artaza, 2007; Barbosa et al., 2011; Stimmer, 2013).

\section{El caso chileno}

En el caso de Chile, Sanhueza y Soto (2009) buscan evidenciar la inserción de este país a Asia-Pacífico al resaltar las misiones diplomáticas y las cámaras de comercio bilaterales presentes en diferentes países de la región, así como los encuentros entre autoridades gubernamentales, la participación en organizaciones y foros multilaterales y la creación de institutos académicos que, desde Chile, trabajan temáticas concernientes a Asia-Pacífico. Estos autores también mencionan algunos documentos del siglo XIX con hechos históricos que dan cuenta de las relaciones diplomáticas entre Chile y Asia-Pacífico. Como complemento a esta información, Sanhueza y Soto (2009) presentan el total de exportaciones e importaciones de países latinoamericanos y asiáticos entre 1990 y 2008. 
Un enfoque similar para el estudio de la inserción de Chile se encuentra en Prieto y Ladino (2014), quienes profundizan en el análisis de datos de comercio exterior e inversión extranjera de ciertos países -incluyendo los de Asia-Pacífico- en Chile y mencionan algunas relaciones diplomáticas de este país, al igual que su participación en foros transpacíficos. Esta última cuestión también la aborda Artaza (2007) y resalta, además, que los acuerdos comerciales y la participación en foros como APEC son procesos de inserción que deben complementarse con vínculos diplomáticos (Artaza, 2007). Sin embargo Ross (2007), tras recopilar diferentes instrumentos de política exterior suscritos durante el periodo 1897-2007 entre Chile y los países del Sudeste Asiático, argumenta que no ha habido una perfecta correlación entre la suscripción de acuerdos bilaterales y la importancia que estos han tenido para el comercio de las partes involucradas (Ross, 2007).

\section{El caso colombiano}

En el caso colombiano, algunos estudios han buscado analizar la inserción de este país en Asia-Pacífico contextualizando previamente las dinámicas extraregionales de América Latina, de manera que el auge de las relaciones entre Colombia y Asia-Pacífico termina siendo una consecuencia del estancamiento de la relación comercial de América Latina con Europa y la disminución relativa de la participación de Estados Unidos en la región latinoamericana (Fernández de Soto y Pineda, 2012).

Ahondando en las relaciones comerciales, Torres (2013) analiza la balanza comercial entre Colombia y los países de la Cuenca del Pacífico (China, Corea y Japón, entre otros), las exportaciones e importaciones manufactureras, las limitaciones productivas del país y su reprimarización productiva ${ }^{5}$. En este sentido, Torres advierte que Colombia

\footnotetext{
5 La reprimarización productiva se refiere a la estrategia de crecimiento económico basada en la exploración y exportación de materias primas, respondiendo así a los altos precios internacionales de las mismas y revirtiendo la estructura comercial exportadora hacia el sector primario (Veltmeyer, 2012)
} 
repite un patrón de desarrollo con Asia-Pacífico ya vivido en épocas anteriores con países industrializados, pues el comercio ha tendido a ser interindustrial al exportar materias primas e importar bienes de capital y manufacturas (Torres, 2013). Esta situación, evidenciada en otros estudios (Fernández de Soto y Pineda, 2012; Bonilla, 2011), ha llevado a que algunos académicos desarrollen trabajos en términos prescriptivos, argumentando entonces que para lograr una mayor y más eficiente inserción es necesario generar cadenas de valor intrarregionales y "fortalecer un tejido productivo de alta intensidad tecnológica" (Fernández de Soto y Pineda, 2012, p. 75).

Por otro lado, Barbosa, Posada y Serrano (2011) se alejan un poco del enfoque meramente económico y evalúan los posibles escenarios de inserción de Colombia aAsia-Pacífico al circunscribir dichos escenarios a los ya existentes (APEC, etc.). Sin embargo, Pastrana, Betancourt y Castro (2014) destacan la necesidad de trascender las dinámicas comerciales y desarrollar también vínculos diplomáticos (Pastrana, Betancourt y Castro, 2014).

En estudios más recientes se ha observado una tendencia a abordar de manera prescriptiva la inserción de Colombia en Asia-Pacífico (Godoy, 2016; González et al., 2016; Calderón, 2016). En este sentido, Godoy (2016) propone a Asia como alternativa para diversificar la política exterior colombiana y disminuir su dependecia de Estados Unidos. En esta misma línea, Calderón (2016) resalta la poca presencia institucional del país en Asia, señalando entonces la importancia de pertenecer a APEC debido a que constituye un espacio para la interacción con miras a diversificar las exportaciones y buscar nuevos mercados. Por otro lado, González y otros (2016) analizan la diversificación de la política exterior colombiana entre los años 2010 y 2014, tomando como variables independientes la participación en organismos regionales, la participación en espacios multilaterales y las estrategias de inserción internacional, entre otras. Sin embargo, esta propuesta no logra dar cuenta de los diferentes ámbitos de inserción del país en Asia-Pacífico, pues estas estrategias se evalúan en términos de la suscripción de TLC (González et al., 2016). 
Por último, es importante retomar el trabajo de Coutin y Terán (2016), quienes analizan los tratados bilaterales de países AP con China, Corea y Japón desde el año 1990. Este estudio, aunque similar en cuanto a la fuente usada, se enfoca en las relaciones comerciales configuradas por medio de tratados, especialmente entre los tres países asiáticos y Colombia.

\section{El caso mexicano}

En cuanto al caso mexicano, Faust y Franke (2002), sin dejar de lado la dimensión económica de la inserción, analizan las relaciones políticas y comerciales entre México y Asia-Pacífico, enfocándose en los vínculos comerciales y en las inversiones, al igual que en los lazos diplomáticos, describiendo los principales hechos. Además, Faust y Franke presentan datos sobre flujos migratorios en siglos pasados para evidenciar la relación entre México y Asia-Pacífico (Faust \& Franke, 2002).

Por otro lado, Romero y Rivera (2013) argumentan que debido a la ubicación geográfica del país, su política exterior ha estado dirigida principalmente a Estados Unidos, lo que ha restringido la inserción a Asia-Pacífico limitándola a la firma de tratados comerciales ${ }^{6}$, sin que esto haya disminuido la dependencia de Estados Unidos (Romero y Rivera, 2013). No obstante, para Rodríguez (2014), la nueva configuración de la región Asia-Pacífico se ha fundamentado en tratados de libre comercio, los cuales, según esta autora, han permitido la inserción de México en dicha región, especialmente durante el proceso de liberalización económica de los noventa, periodo en el que se abrieron nuevos espacios de cooperación económica en Asia-Pacífico (Rodríguez, 2014). Por su parte, León-Manríquez y Tzili Apango (2015) se proponen "analizar la trayectoria económica y política de la relación de México con Asia-Pacífico” (León-Manríquez y Tzili

\footnotetext{
6 Jugurnath, B., Stewart, M. y Brooks, R. (2007) analizan el efecto de los tratados regionales suscritos entre los años 1980 y 2000. Este análisis de carácter empírico se concentra en tratados comerciales, de manera que se evalúa el efecto que bloques como ASEAN y APEC han tenido sobre el libre comercio, ya sea generando trade creation o trade diversion.
} 
Apango, 2015, p. 114), para lo que mencionan algunos tratados con el propósito de resaltar la antigüedad de las relaciones de México con ciertos países asiáticos y —al igual que Romero y Rivera (2013) y Rodríguez (2014) - presentan como indicadores que dan cuenta de las relaciones bilaterales las importaciones y exportaciones y la inversión extranjera directa.

\section{El caso peruano}

En los estudios en torno al caso peruano se mantiene el énfasis sobre las dinámicas comerciales, tal como en los otros tres casos. Sin embargo, Gago (2001) enmarca dentro del interregionalismo las relaciones comerciales de Perú en Asia-Pacífico, pues analiza dichas relaciones - en términos de importaciones y exportaciones-, a la luz de acuerdos de integración regional como Mercosur y el Pacto Andino. Adicionalmente, Stimmer (2013) señala como forma de inserción la participación de Perú en organizaciones americanas-asiáticas como el Consejo Económico de la Cuenca del Pacífico (PBEC), organización no gubernamental fundada en 1967 y de la cual hacen parte los países aquí estudiados; el Foro de Cooperación Económica Asia-Pacífico (APEC), fundado en 1989, en donde participan los Estados de Chile, México y Perú; y más recientemente, el TPP ${ }^{7}$. Stimmer (2013) mantiene el énfasis en los temas comerciales, argumentando que la variación en el nivel de exportaciones e importaciones entre diferentes países de Asia-Pacífico se presenta como medida de interregionalismo.

Por otro lado, Ferrero (2014), quien señala que Perú es uno de los países de América Latina con relaciones más cercanas y longevas con Asia, y en particular con China, Corea y Japón, da especial relevancia a los organismos multilaterales dentro del proceso de inserción, particularmente a APEC, foro que, de acuerdo con este autor, ha permitido una mayor inserción en Asia-Pacífico, especialmente en los ámbitos económicos y financieros. Adicionalmente, Ferrero (2014) menciona los acuerdos de libre comercio que para ese entonces (2014) se estaban negociando entre

\footnotetext{
El TPP fue finalmente firmado en 2016 por representantes de los 12 Estados que hacen parte del acuerdo megaregional, entre ellos, Chile, México y Perú.
} 
Perú y algunos bloques económicos, y menciona de manera maginal otros acuerdos que incluyen temas diferentes a los comerciales (Ferrero, 2014). Wise (2016) retomará los acuerdos comerciales, específicamente el tratado de libre comercio negociado entre Perú y China en el 2009. A partir de su análisis, la autora puntualizará en el carácter Sur-Sur del tratado, así como en la nueva agenda comercial a la que dará lugar.

\section{Propuesta frente a la primacía del enfoque económico en la literatura analizada}

Como se resaltó en los párrafos anteriores, existe una primacía de los enfoques económicos y comerciales en la literatura referida a la inserción de países miembros de la AP en Asia-Pacífico. En particular, en el tema que se refiere al análisis de tratados, ese enfoque es preponderante. Lo anterior se explica, entre otras razones, en la medida en que la región Asia-Pacífico se ha convertido en un socio comercial cada vez más importante: para el primer semestre de 2015, las exportaciones totales de América Latina y el Caribe a esta región representaban el $18 \%$ y las importaciones el $31 \%$ (Observatorio América Latina-Asia Pacífico, s.f.). Para países como Colombia y México dichas relaciones comerciales implican una importante fuente de diversificación de socios.

Al partir de dicho reconocimiento, es necesario resaltar la falta de otro tipo de literatura que no se enfoque en las relaciones e intercambios comerciales para estudiar la inserción de estos países en Asia-Pacífico. La misma se ha invisibilizado o se le ha restado importancia. Lo que intenta hacer este documento es realizar un aporte inicial para cerrar esa brecha de conocimiento. Lo anterior se hará, como ya se mencionó, a través de un análisis macro de los tratados bilaterales que han celebrado los miembros de la AP con sus contrapartes asiáticas.

Con esta iniciativa se identificará la diversidad de temáticas incluidas en los tratados bilaterales que vinculan a los países casos de estudio. Dicha diversidad se ha dejado de lado debido al sesgo comercial de las relaciones que se enmarcan en el regionalismo abierto (Briceño, 2013). Aunque es un hecho evidente la existencia de esa diversidad, 
este artículo es pionero en proponerla como un objeto de estudio que puede servir como un valioso indicador de la inserción de los países miembros de la AP en Asia-Pacífico.

\section{Los intereses de los Estados en el ámbito internacional identificados a través de los tratados que celebran}

En esta sección se expondrá una justificación acerca de la relevancia del análisis de los tratados bilaterales de los miembros de la AP con sus contrapartes asiáticas. Dicha justificación se complementará con una característica endógena de la AP, que se expresa en su documento fundacional. Finalmente, se propondrá un breve análisis comparado de la posición que tienen los tratados en los sistemas jurídicos de cada uno de los miembros de la AP, buscando resaltar las implicaciones que tiene lo anterior en relación con la política exterior de los Estados.

\section{Los tratados bilaterales}

Desde el nacimiento de la concepción actual de Estado, el derecho internacional - y los tratados - aparece dada la necesidad de los Estados de relacionarse (Irigoitia, 2014). Desde el punto de vista normativo los tratados se consideran — junto con la costumbre- los principales métodos de creación de normas internacionales vinculantes. Las diferencias principales, como lo arguye Cassese (2005), son dos: (1) los tratados solo tienen aplicación entre las partes contratantes; y (2) pueden regular cualquier materia en la forma que estas elijan. En la generalidad se puede apreciar que la mayoría de los miembros de la comunidad internacional prefiere los tratados para establecer sus relaciones en la medida en que sus preceptos son más ciertos y derivan de negociaciones (Cassese, 2005).

Los tratados bilaterales se forman por Estados negociadores o contratantes, los cuales toman parte en la elaboración y adopción del texto. En este sentido, un tratado bilateral es más parecido a un contrato que a una legislación nacional en tanto este solo es vinculante para 
los Estados que han consentido en obligarse (Aust, 2010), lo que se conoce como efecto interpartes.

En ese sentido, un Estado contratante es el que ha accedido a obligarse por un tratado. Para ello existen dos requisitos necesarios: el consentimiento en obligarse y el perfeccionamiento del tratado (Aust, 2010). El primero puede expresarse a través de una gran diversidad de formas, algunas de las más comunes son la suscripción, el intercambio de notas diplomáticas, la ratificación por parte de autoridades con facultades para obligar al Estado, entre otras; el segundo depende en gran medida de las reglas nacionales de cada Estado que generalmente son las mismas normas para aprobar la legislación doméstica. Este punto es de especial importancia dado que los tratados, para ser ratificados, son sometidos a la ingeniería institucional de cada Estado.

Lo anterior pone en evidencia que un tratado internacional celebrado por Estados posee naturaleza de acto jurídico con valor simultáneo en el derecho interno de los Estados parte y en el derecho internacional, lo que determina en buena medida su relevancia en torno a las relaciones de los Estados. Por ello, en los sistemas constitucionales por lo general existen normas aplicables a la regulación de los tratados desde la perspectiva interna (Menéndez, 2005) ${ }^{8}$. En otras palabras, la entrada en vigor de un tratado bilateral depende fundamentalmente de la regulación nacional porque los Estados buscan maximizar su libertad en dichas materias (Cassese, 2005). En este sentido, es relevante realizar un breve análisis de la regulación constitucional de las relaciones internacionales y los tratados en los países miembros de la AP.

En relación con lo anterior, finalmente es necesario resaltar que los tratados bilaterales tienen una importancia endógena para la AP. En el Acuerdo Marco, documento que le da personalidad jurídica al mecanismo

\footnotetext{
8 En sentido contrario argumenta Conforti (2001), para quien el derecho internacional impregna todos los aspectos internos de los Estados, incluso la forma en que estos entran en vigor (Conforti, 2001). No obstante, lo que se observa, por lo menos para los países de la AP, es que la legislación doméstica tiene un rol central.
} 
de integración, se expone que "el proceso de integración tendrá como base los acuerdos económicos, comerciales y de integración vigentes" (Alianza del Pacífico, 2012). Estos incluyen los que tienen los socios de la AP con terceros Estados, como lo son China, Corea y Japón. Este criterio endógeno representa un punto de partida para realizar estudios como el presente $y$, de hecho, el mismo refuerza la relevancia del análisis y caracterización de los tratados propuestos.

Esa directriz del mecanismo de integración también se observa en uno de sus tres objetivos centrales que es "convertirse en una plataforma de articulación política, integración económica y comercial, y proyección al mundo, con énfasis en la región Asia-Pacífico" (Alianza del Pacífico, 2016). Aparte del enfoque específico en dicha región, se puede destacar que, además de ser un proyecto de integración económica y comercial, la AP se propone como una plataforma de articulación política y con proyección al mundo, las cuales tienen que darse necesariamente sobre las bases de las relaciones establecidas por los países miembro antes de ser parte del proceso. Estas razones dan cabida al desarrollo de estudios que tengan como datos principales los tratados bilaterales. Resaltado el anterior punto, a continuación se muestran datos empíricos que permiten operacionalizar la discusión planteada y los conceptos indicados.

\section{Análisis comparado de la regulación constitucional de los tratados por los miembros de la Alianza del Pacífico}

El análisis en esta sección está restringido a la determinación de las relaciones entre política exterior y tratados públicos y tendrá como referente central el libro de Germán Ramírez Bulla (1999), uno de los pocos textos que se ocupa del tema desde una perspectiva comparada. Adicionalmente, se tiene como punto de partida la anuencia con la premisa de Ramírez (1999) de que la celebración de tratados es el principal resultado normativo del proceso de toma de decisiones en la política exterior ${ }^{9}$. Sin embargo, es claro también que dicha

\footnotetext{
9 En este texto se entiende la política exterior desde la concepción sistémica de Easton (1957), donde la misma es una política pública (policy) o un producto (output) de un sistema
} 
política no se reduce a la firma y ratificación de tratados internacionales, sino que su estudio representa un interesante aporte para el análisis de las tendencias o particularidades de la misma (Milanese y Fernández, 2012).

Teniendo en cuenta esa aclaración, se parte del entendimiento de que los tratados ratificados representan un indicador razonablemente fiable de las tendencias de la política exterior, debido a que los gobiernos llevan a cabo una amplia y creciente proporción de sus relaciones exteriores a través de acuerdos formales (Slaughter, Tulumello y Wood, 1998). La anterior idea es compartida por Milanese y Fernández (2012) y se acoge en el presente texto.

Cuando los Estados participan en procesos de creación de normas no lo hacen con la intención de establecer normas internacionales. Su preocupación principal es la de garantizar sus intereses económicos, sociales o políticos, lo que tiene como consecuencia inconsciente e involuntaria la creación de normas (Cassese, 2005). Esos intereses son los que dan forma a la política exterior y que regularmente se cristalizan en tratados.

Al respecto, una de las cuestiones fundamentales planteadas dentro de la jurisprudencia del derecho internacional es el de la fuente de la obligación de cumplir. Dentro de un marco positivista moderno, la fuente de vinculatoriedad es el consentimiento de los propios Estados (Scott, 2005). Dicho consentimiento se regula en el derecho interno en la forma prevista por cada Constitución (Monroy, 2008), en la medida en que el perfeccionamiento de los tratados depende de esas regulaciones. Teniendo claridad en lo anterior, para desarrollar el objetivo del análisis de derecho comparado de las normas constitucionales que regulan los tratados, es necesario introducir una breve

político particular que responde a insumos (inputs) y presiones del medio ambiente, donde se encuentran actores domésticos e internacionales que pueden influir en la toma de decisiones. En coherencia con lo anterior, si bien la política exterior de los miembros de la AP no se reduce a la participación de estos en el mecanismo de integración, sí incluye todas las acciones dirigidas en ese sentido (Terán, 2016). 
consideración metodológica. Posteriormente se realizará el análisis empírico sucinto usando como base los textos constitucionales de los miembros de la AP.

\section{Micro comparación en el derecho comparado}

El derecho comparado se propone, por su objeto, confrontar el conjunto de las reglas de derecho desde las perspectivas de las fuentes de derecho (Gómez, 2009). En ese sentido, se busca identificar algunas particularidades de la regulación constitucional de los tratados en los países miembros de la AP, por ser ella la fuente principal. Dicha comparación se posibilita en la medida en que los países miembros de la AP pertenecen a la misma familia jurídica neorromanista (UNAM, 2011).

La comparación que se propone está enmarcada en la técnica de microcomparación que se entiende como el proceso por el cual se contrastan instituciones, procesos y procedimientos concretos y específicos, cuya finalidad es la de aportar microresultados aterrizados a problemas concretos (Torres, 2011). Este punto de vista es compartido por Sweigert (2002), quien muestra que la microcomparación busca soluciones a problemas concretos; para este fin se analiza la forma en que las instituciones pueden resolverlos (Sweigert, 2002). Por ello las investigaciones llevadas a cabo con ese enfoque se dan a nivel de las partes de los sistemas legales y no en su totalidad (Van Laer, 1998). Esa es la posición general al respecto de este tipo de comparación, la cual guiará la que se propone a continuación.

\section{Breve análisis comparado de los textos constitucionales de los miembros de la AP}

Partiendo de esos puntos en común, el problema central del análisis en esta parte es, como ya se indicó, identificar las particularidades de los tratados a través del estudio de las normas constitucionales ${ }^{10}$ referidas a ese tema particular.

\footnotetext{
10 Por la naturaleza del presente artículo, y teniendo en cuenta la técnica de la microcomparación, solo se tomarán como datos empíricos algunos artículos de las constituciones y
} 
$\mathrm{Al}$ respecto, en el cuadro que se presenta a continuación, se observan cuatro categorías de análisis sobre las cuales se concentrará el estudio de cada Constitución. En relación a las modalidades de incorporación se presentan dos modelos: la incorporación automática, en la que el acto de autorización por el poder legislativo y del presidente introducen en el derecho interno las normas convencionales, y solo queda pendiente para su plena aplicabilidad la publicación en el boletín oficial. El segundo, la incorporación legislativa, hace referencia a que las normas internacionales son aplicables cuando los legisladores aprueban los tratados pasando legislación que los implementa en el ámbito nacional ${ }^{11}$ (Menéndez, 2005; Cassese, 2005). En resumen, la diferencia radica en si el tratado entra en vigor a través del proceso de aprobación de leyes o no.

Enseguida se introducen dos criterios que responden a la intervención de las otras ramas del poder público, por ello se tiene la consideración del tipo de control constitucional y del actor con primacía para promover la firma de tratados y dirigir la política exterior. La tabla se presenta a continuación:

Tabla 1: Análisis comparado de la regulación constitucional de los tratados y las relaciones internacionales en países AP

\begin{tabular}{|l|l|l|l|l|}
\hline & $\begin{array}{c}\text { Incorporación } \\
\text { automática }\end{array}$ & $\begin{array}{c}\text { Incorporación } \\
\text { legislativa }\end{array}$ & $\begin{array}{c}\text { Control } \\
\text { constitucional }\end{array}$ & $\begin{array}{c}\text { Actor con } \\
\text { primacía }\end{array}$ \\
\hline Chile & No & Sí & Previo & Presidente \\
\hline Colombia & No & Sí & Previo & Presidente \\
\hline México & No & Sí & N/A & Presidente \\
\hline Perú & No & Sí & Represivo & Presidente \\
\hline
\end{tabular}

Fuente: elaboración propia con base en las constituciones de los cuatro países.

se desarrollará un análisis breve de estos. Esto presenta una restricción en la medida en que se dejan por fuera varios artículos que posibilitarían un análisis sistemático y, asimismo, la jurisprudencia, fuente fundamental para interpretar las constituciones. Lo anterior deja un campo amplio para complementar el estudio.

11 No se hará énfasis en las discusiones acerca de si los sistemas legales son de corte monista o dualista debido a que, siguiendo a Cassese (2005) y Aust (2010), las mismas han quedado en el pasado y muchas constituciones contienen elementos de ambos conceptos. 
Lo primero que se puede observar es que ningún sistema jurídico incorpora automáticamente los tratados, esto implica que los congresos de los países miembro de la AP juegan un rol central en la aprobación de los mismos. Por ejemplo, la Constitución de Chile, en su Artículo 54, numeral 1, expone que dentro de las atribuciones exclusivas del Congreso está "aprobar o desechar los tratados internacionales que le presentare el presidente de la República”. En Colombia, el Artículo 150, numeral 16, dicta que corresponde al Congreso "aprobar o improbar los tratados que el Gobierno celebre". En un sentido similar, la constitución mexicana ${ }^{12}$ en el Artículo 76, numeral I, expone que son facultades exclusivas del Senado "analizar la política exterior desarrollada por el Ejecutivo Federal [...] y aprobar los tratados internacionales". Finalmente, en el Artículo 56 de la constitución peruana expone que los tratados "deben ser aprobados por el Congreso antes de su ratificación por el presidente de la República"13 y, en el Artículo 102, numeral 3, que el Congreso tiene la atribución de "aprobar los tratados, de conformidad con la Constitución".

Al respecto del control constitucional se evidencia una variedad interesante. Para el caso de Chile, la reforma constitucional de 2005 mantuvo el control preventivo, de carácter facultativo, de los tratados internacionales por parte del Tribunal Constitucional (Ramírez, 1999; Peña, 2007), contenido en el Artículo 93, numeral 3 de la Constitución. Característica común con Colombia, donde la Carta Política establece que posterior a la aprobación del tratado por medio de una ley expedida por el Congreso, pero anterior a la manifestación del consentimiento en obligarse, la Corte realizará un control de exequibilidad preventivo (García, 2005; Monroy, 2008).

Para México esta categoría no aplica en la medida en que no existe un Tribunal Constitucional que, en el tema de los tratados, vele por

\footnotetext{
12 Para referirse al texto constitucional mexicano es necesario tener en cuenta la organización federal del Estado.

13 Este artículo especifica cinco grandes temáticas referidas a los tratados en las cuales el Ejecutivo debe presentar para aprobación la norma al Congreso, si la misma trata un tema diferente no es necesaria esa aprobación.
} 
la supremacía constitucional, establecida en el Artículo 133 superior. Por ello dicha garantía se debe dar por parte del Ejecutivo o el Legislativo a través de un control a posteriori o represivo ${ }^{14}$ (Alzate, 2002; Rodríguez, 2013; Ramírez, 1999). Este mismo tipo de control se presenta en Perú, con la gran diferencia de que existe Tribunal Constitucional. En este caso el Tribunal reacciona a una demanda constitucional de un tratado que solo puede ser interpuesta a partir de la publicación de la norma cuestionada en el Diario Oficial, último requisito de entrada en vigencia de las leyes.

Finalmente, el cuadro confirma la teoría general que dicta que existe un predominio de la corriente constitucional según la cual el Ejecutivo es el encargado de negociar y firmar los tratados ${ }^{15}$ y el Legislativo es el que tiene el cometido de impartirles su aprobación a efecto de que aquel pueda proceder a ratificarlos y así manifestar el consentimiento del Estado en la órbita del derecho internacional (Vargas, 2009). Si bien el Congreso en materia de política exterior es el contrapeso del Ejecutivo (Trejo, 2006), los ejecutivos, particularmente los presidentes, están estructuralmente mejor posicionados para impactar sobre el proceso de toma de decisiones en el campo de la política exterior (Milanese, 2007).

\footnotetext{
14 Se ha argumentado que resultaría inconveniente la posibilidad de un control de constitucionalidad a posteriori, ya que dicha alternativa podría coadyuvar al vaciamiento del contenido axiológico y jurídico de la exigencia que se impone a todo Estado en el sentido de honrar sus compromisos internacionales (Bazán, 2003).

$15 \mathrm{Al}$ respecto de este punto la Constitución chilena dicta que el presidente tiene la potestad de "concluir, firmar y ratificar los tratados que estime convenientes para los intereses del país" (Artículo 32, numeral 15). En Colombia, el presidente tiene la facultad de "dirigir las relaciones internacionales $[. .$.$] y celebrar con otros Estados y entidades de derecho interna-$ cional tratados o convenios" (Artículo 189, numeral 2). La Constitución mexicana expone entre las facultades y obligaciones del presidente, “[...] dirigir la política exterior y celebrar tratados internacionales" (Artículo 89, fracción X). De igual forma lo hace la Constitución peruana al preceptuar que el presidente tiene la potestad de "dirigir la política exterior y las relaciones internacionales; y celebrar y ratificar tratados” (Artículo 118, numeral 11).
} 


\section{Presentación de resultados}

\section{Metodología en la construcción de la base de datos de los tratados}

Como ya se indicó, el levantamiento de los tratados bilaterales celebrados entre los países casos de estudio se realizó de las bases de tratados virtuales y de acceso público de las cancillerías de cada país miembro de la AP y de un levantamiento en campo realizado en el Ministerio de Relaciones Exteriores de Perú.

La información de los tratados internacionales fue sistematizada y para que las bases de datos fueran comparables, se integraron y homogenizaron las temáticas de análisis como un primer filtro. El segundo filtro fue crear categorías macro que abarcaran una variedad amplia de las temáticas homogenizadas con la finalidad de sistematizar la información, lo que permite una mejor interpretación de la misma. La siguiente tabla sintetiza lo escrito.

A continuación se explicarán algunas cuestiones que necesitan profundización. Al respecto de las categorías, inicialmente se hizo una diferenciación entre donaciones y cooperación. Esto es importante en la medida en que estas podrían tratarse en conjunto, pero se desagregaron debido a los temas incluidos en cada categoría, donde la primera hace referencia a dinero donado por los países asiáticos a los latinoamericanos, mientras que la segunda hace referencia a distintas temáticas donde los países cooperan. Dentro de la categoría de cooperación es importante precisar que la cooperación financiera hace referencia a préstamos, por lo que no fue incluida en la categoría de donación.

En la categoría de comercio se incluyen los tratados que abordan el tema fitosanitario, el cual es entendido como una barrera no arancelaria al comercio (BID, 2016). En ese sentido se espera que los tratados que incluyen este tema dinamicen el comercio. El tema de eliminación de reservas hace referencia a un tratado particular de México en el que estas se eliminan frente a la adhesión de China a la Organización Mundial del Comercio (OMC). Por su parte, la categoría de inversión incluye los comúnmente conocidos como Bilateral Investment Treaties 
Tabla 2: Categorías de análisis

\begin{tabular}{|c|c|c|}
\hline Categorías & \multicolumn{2}{|l|}{ Temáticas incluidas } \\
\hline Donación & \multicolumn{2}{|c|}{ Tratados en los que los países asiáticos realizan donaciones en dinero } \\
\hline & \multicolumn{2}{|l|}{ Cooperación cultural } \\
\hline & \multicolumn{2}{|l|}{ Cooperación espacial } \\
\hline & \multicolumn{2}{|l|}{ Cooperación financiera (créditos) } \\
\hline Coupcracion & \multicolumn{2}{|l|}{ Cooperación jurídica } \\
\hline & \multicolumn{2}{|l|}{ Cooperación técnica y científica } \\
\hline & \multicolumn{2}{|l|}{ Voluntariado } \\
\hline \multirow{3}{*}{ Comercio } & \multicolumn{2}{|l|}{ Cooperación fitosanitaria } \\
\hline & \multicolumn{2}{|l|}{ Eliminación de reservas } \\
\hline & \multicolumn{2}{|l|}{ TLC } \\
\hline \multirow[b]{2}{*}{ Inversión } & \multicolumn{2}{|l|}{$\mathrm{BIT}$} \\
\hline & $\begin{array}{l}\text { Cooperación tributaria y } \\
\text { aduanera }\end{array}$ & $\begin{array}{l}\text { Asistencia administrativa mutua, } \\
\text { evitar la doble tributación y prevenir } \\
\text { la evasión fiscal }\end{array}$ \\
\hline Movilidad & $\begin{array}{l}\text { Movilidad de personas, visados } \\
\text { y transporte }\end{array}$ & $\begin{array}{l}\text { Exención de visas a diplomáticos, } \\
\text { movilidad para capacitaciones, } \\
\text { reconocimiento de estudios, } \\
\text { reconocimiento de licencias de } \\
\text { conducir, transporte aéreo y } \\
\text { marítimo y turismo }\end{array}$ \\
\hline \multirow{4}{*}{ Otros } & \multicolumn{2}{|l|}{ Protección de bienes culturales } \\
\hline & \multicolumn{2}{|l|}{ Protección del medio ambiente } \\
\hline & \multicolumn{2}{|c|}{ Relaciones diplomáticas y consulares } \\
\hline & \multicolumn{2}{|c|}{ Usos pacíficos de la energía nuclear } \\
\hline
\end{tabular}

Fuente: elaboración propia.

o BIT (por sus siglas en inglés) y los acuerdos de cooperación tributaria y aduanera, que tratan los temas del descriptor del cuadro.

La categoría de movilidad engloba una diversidad de temas que centralmente facilitan la movilidad de las personas, incluso con acuerdos referidos al transporte de personas por varios medios y tratados relacionados con la facilitación del turismo. Finalmente, la categoría otros incluye temas misceláneos en los cuales se presentan algunos tratados insulares. Finalmente es necesario aclarar que algunas temáticas no 
se encuentran en todos los casos, otras son insulares y se las deja por fuera por aparecer una única vez y en un solo caso.

\section{Análisis cuantitativo de los tratados bilaterales entre los casos de estudio}

En la tabla 3 se presentan los porcentajes de tratados firmados por Chile, Colombia, México y Perú con China, Corea y Japón entre los años 1990 y 2016. Estos tratados se agrupan en las categorías definidas anteriormente. Si bien la cantidad de tratados se presenta en términos porcentuales para facilitar la comparación entre los cuatro países, es importante precisar que, en el caso de Chile, los acuerdos totales firmados en el periodo de análisis fueron 56, para Colombia fueron 63, mientras que para México y Perú fueron 23 y 216, respectivamente. Esta diferencia en el número de tratados bilaterales evidencia una mayor inserción de Perú en Asia-Pacífico.

Las bases para la mayor inserción peruana fueron sentadas durante el gobierno de Fujimori (1990-2000), periodo en el que se celebró el 49,3\% de los tratados, presentando así un gran dinamismo las relaciones Lima-Tokio formalizadas a través de estos instrumentos. Este activismo en la negociación y ratificación de tratados permitió la profundización de los vínculos con Asia-Pacífico y buscó posicionar a Perú como "país-puente" (Guerra, 2014). Asimismo, con Fujimori quedaría establecido el esquema para construir y desarrollar vínculos sólidos con Asia-Pacífico (Guerra, 2014).

Colombia, por su parte, es el segundo país con mayor número de tratados con Asia-Pacífico, sin embargo, una de las primeras aproximaciones formales de este país a la región se dio durante el gobierno de Samper (1994-1998), periodo en el que se hizo explícito el interés por hacer parte de APEC. No obstante, solo a partir del año 2010, durante el primer gobierno de Santos (2010-2014), se definió una estrategia de aproximación, la cual tomaría forma con la Alianza del Pacífico (Pastrana, Betancourt y Castro, 2014). Es interesante resaltar aquí que durante la administración de Samper se celebró el 22,2 \% de los tratados bilaterales, mientras que en la administración de Santos, 
actualmente en un segundo periodo de gobierno, se ha celebrado el $15,9 \%, 17,5$ puntos porcentuales menos que en la administración del expresidente Uribe (2002-2010).

En el caso de Chile, es importante resaltar que, si bien es el país latinoamericano que ha desarrollado relaciones comerciales más profundas con Asia-Pacífico (Prieto y Ladino, 2014), no es el que cuenta con mayor número de tratados bilaterales con los países de dicha región, cuestión que corrobora el estudio realizado por Ross (2007) (ver sección El caso chileno). Igualmente, cabe señalar aquí que el 64,4\% de los tratados se concentran entre los años de 1994 y 2006, periodo que comprende las administraciones de Ruiz-Tagle (1994-2000) y Lagos (2000-2006).

En cuanto a México, la cantidad total de tratados celebrados entre 1990 y 2016 expresa claramente la dificultad de este país para diversificar su relaciones exteriores y establecer vínculos con Asia-Pacífico (Romero y Rivera, 2013). De aquí que su cercanía con Estados Unidos sea considerada, desde una perspectiva política, una limitación a estos intentos de diversificación (Faust y Franke, 2002), de hecho, ningún periodo entre 1990 y 2016 tuvo una concentración particularmente alta de tratados.

Las dinámicas descritas agrupan el activismo en la ratificación de tratados a través del tiempo en varios temas. Si se enfoca el análisis en las categorías creadas para la sistematización, se evidencia una realidad que se extiende en todo el periodo de tiempo: los tratados de donaciones representan cerca de la mitad de todos los tratados bilaterales que vinculan a los países bajo estudio, lo que manifiesta la relevancia de este tema en las relaciones entre los países. Otra gran parte de los tratados, un cuarto de estos, trata el tema de cooperación. Estas dos categorías representan el $72 \%$ de los tratados frente al $9 \%$ de los tratados de comercio. Lo descrito se observa en el siguiente gráfico: 


\section{Gráfico 1: Porcentaje de tratados agrupados por categorías}

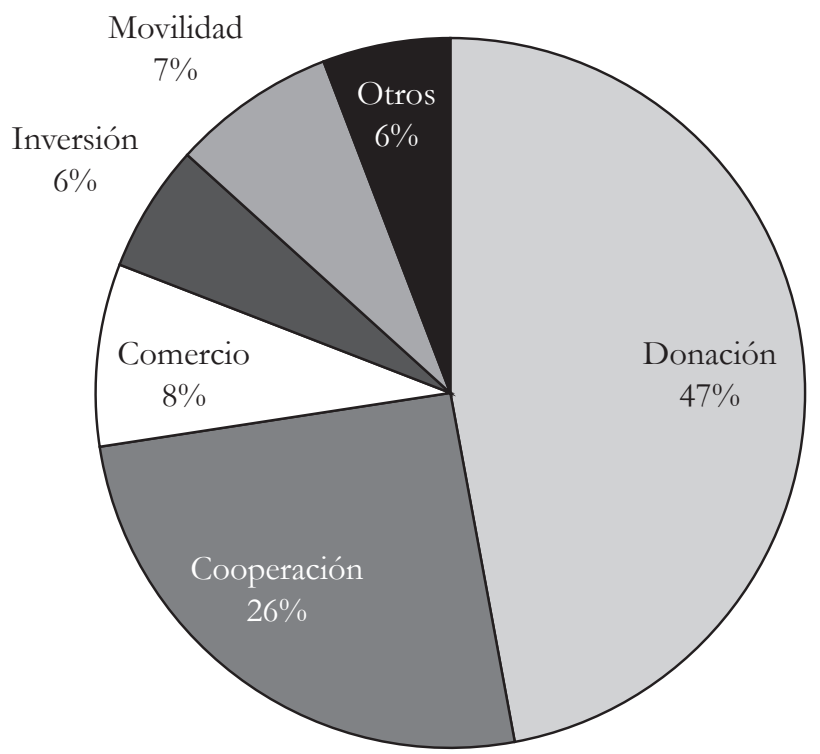

Fuente: Elaboración propia a partir de revisión de tratados.

Con lo anterior, es posible comprobar que el acercamiento entre los países de la Alianza del Pacífico y Asia-Pacífico no ha sido meramente comercial. Igualmente, es interesante resaltar que los tratados comerciales predominan en los países con menor número de tratados: el 26,8 \% de los tratados de Chile con Asia-Pacífico corresponde a esta categoría y el 17,4 \% para el caso de México, mientras que en Perú, el país con mayor número de tratados, aquellos referidos a temáticas comerciales son el 3,7\% (gráfico 2).

Si se consideran los resultados totales, Chile y Perú son los países que tiene una posición ventajosa basada en sus tratados bilaterales de comercio, donde Colombia aparece en un tercer lugar y México en el cuarto (gráfico 2). No obstante, si se profundiza en la indagación se puede observar que Colombia es un caso atípico entre los socios de la AP porque es el único que no cuenta con algún TLC bilateral, instrumento esencial en el tema comercial. Asimismo presenta una situación de desventaja ya que el tratado del tema estandarizado como 
cooperación tributaria y aduanera es más restringido que el de sus socios debido a que trata el tema de la doble imposición y la evasión fiscal, no una cooperación aduanera más amplia. Ello se refleja en que de los países miembros de la AP proveedores de bienes a AsiaPacífico en 2013, Colombia ocupa el cuarto lugar con 1,9\% de la participación, superado ampliamente por Chile (20,6\%), México $(10,1 \%)$ y Perú $(6,3 \%)$. Asimismo los tres últimos países hacen parte del grupo de los principales orígenes de las exportaciones a esa región (Tremolada, 2014).

Por su parte, en el tema de inversión, la situación presenta una variación. México tiene más tratados referidos al tema (38 \%) y Chile y Perú tienen la misma proporción (25\%), lo que deja a Colombia relegado $(13 \%)$. Con base en lo anterior se puede observar que, de los socios en la AP, Colombia no tiene suficientemente desarrolladas las herramientas jurídicas que permitan dinamizar sus relaciones comerciales con las contrapartes asiáticas, en cambio Chile y Perú tienen una posición privilegiada en ese sentido, seguidos de México, a pesar de la importancia de su relación con Estados Unidos en términos económicos.

\section{Gráfico 2: Porcentaje de tratados por país y categoría}

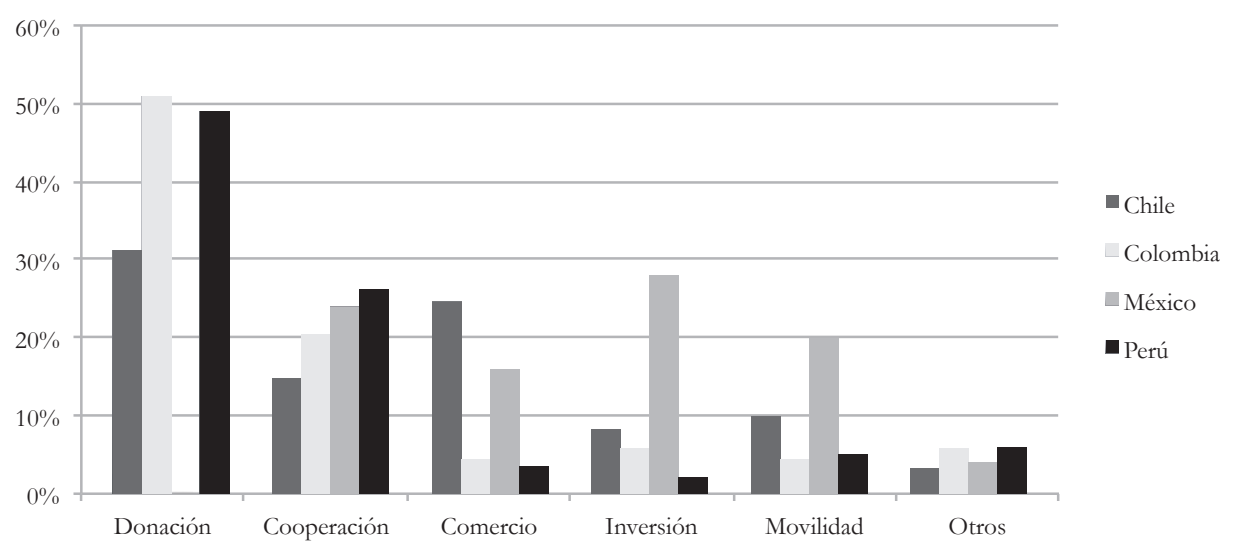

Fuente: Elaboración propia a partir de revisión de tratados. 
De acuerdo a estos contrastes, es preciso preguntarse, siguiendo la diferenciación propuesta por Aminian et al. (2009), si la integración de los países de la Alianza del Pacífico con Asia-Pacífico ha seguido patrones diferentes, oscilando entre el mercado y los acuerdos como dos medios de inserción diferentes.

Al observar la participación de los tres países asiáticos dentro de cada categoría (tabla 4), es importante señalar que China celebró el $65 \%$ de sus tratados referidos a donación con Perú y el 35\% con Colombia, mientras que con Chile y México no suscribió ningún tratado en esta categoría entre 1990 y 2016. Un orden similar se observa en la categoría de cooperación, pues nuevamente Perú y Colombia fueron los países con mayor porcentaje de tratados celebrados con China, $67 \%$ y $16 \%$ respectivamente; por su parte, Chile y México suscribieron el $7 \%$ y $9 \%$ de tratados en esta categoría con el gigante asiático.

Dentro de la categoría de comercio, Japón suscribió el mayor porcentaje de tratados con Chile $(75 \%$ ) y Perú $(25 \%)$, mientras que con Colombia y México no celebró ninguno. En cuanto a la inversión, la situación cambia para México, pues no solamente es el país con mayor porcentaje de tratados celebrados en esta categoría (gráfico 3), sino que además, tanto China como Corea suscribieron el mayor porcentaje de tratados con este país, $38 \%$ y $30 \%$ respectivamente. En el caso de Japón, la mayoría de tratados referidos a inversión fue suscrita con Perú (50 \%). 
Gráfico 3: Porcentaje de tratados entre países de la Alianza del Pacífico y contrapartes asiáticas

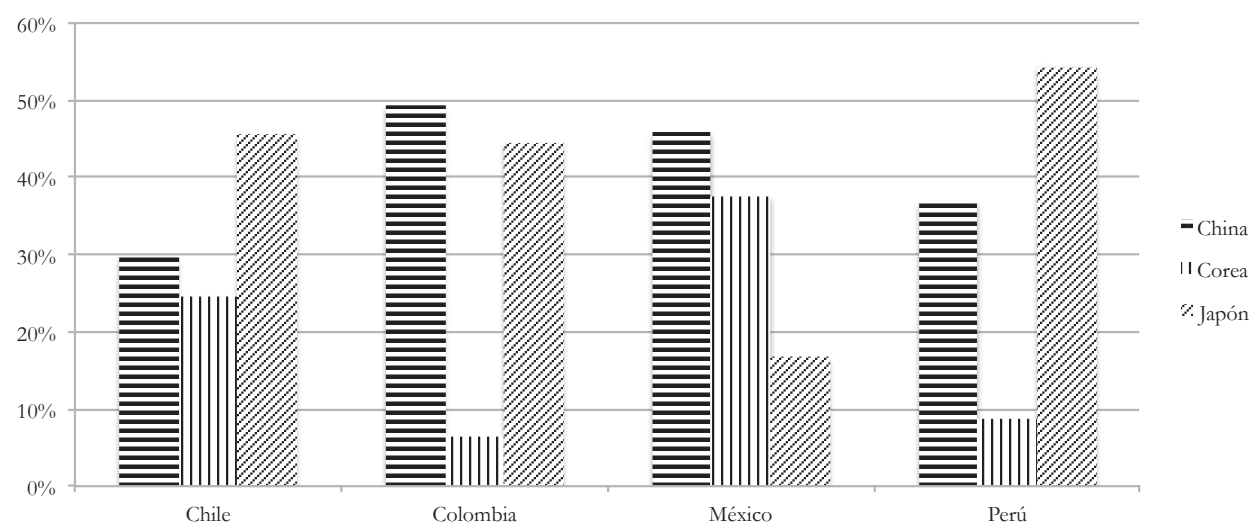

Fuente: Elaboración propia a partir de revisión de tratados

En la categoría de movilidad, China celebró el $50 \%$ de los tratados con Perú, Corea el 38 \% tanto con Chile como con Perú, mientras que Japón suscribió la totalidad de estos tratados con Colombia y Perú. Por último, en la categoría otros, se observa que China celebró el $63 \%$ de estos tratados con Perú, Corea celebró el $33 \%$ con Chile, al igual que con México y Perú, mientras que Japón celebró el 78 \% con Perú. 


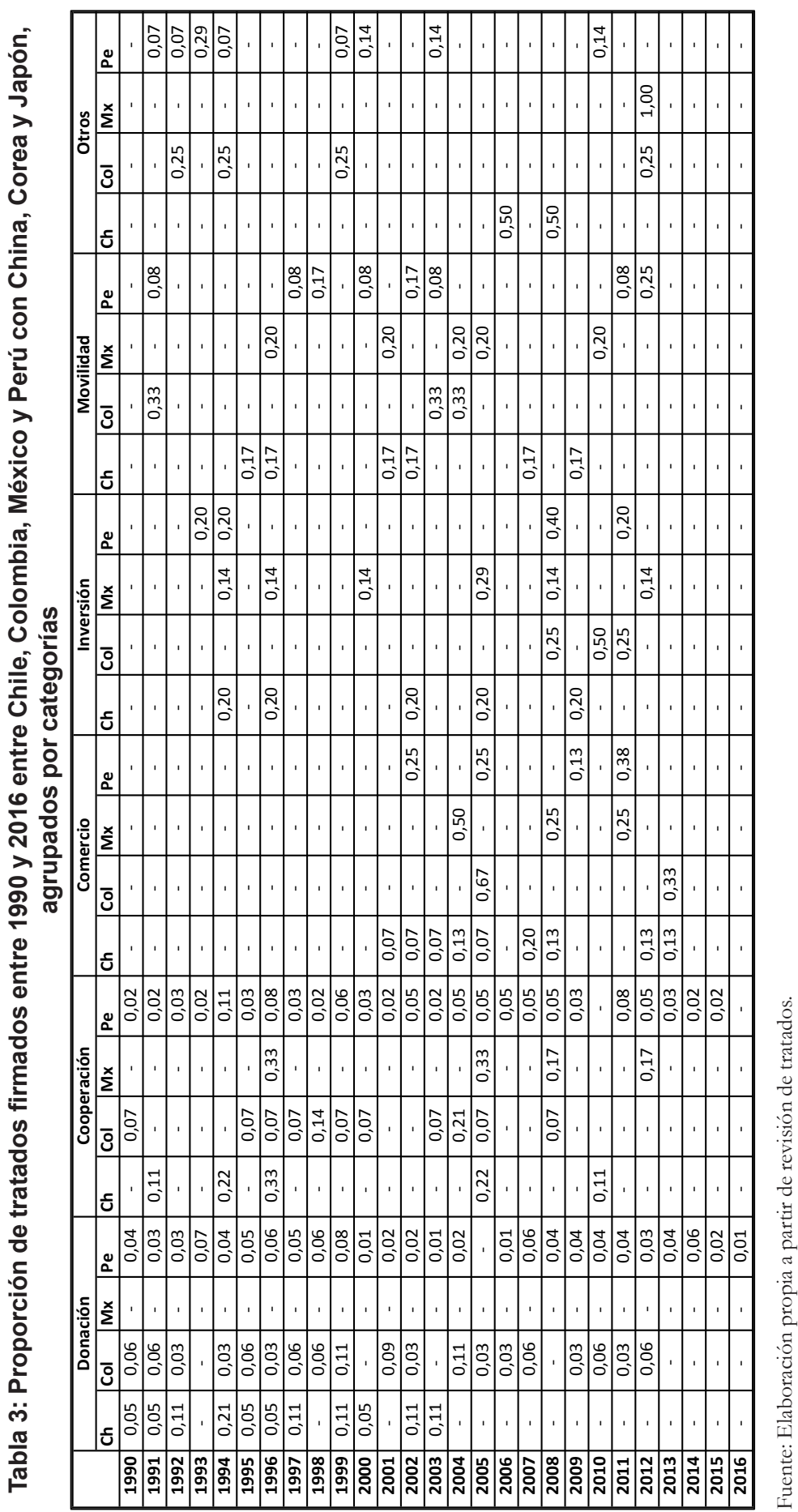




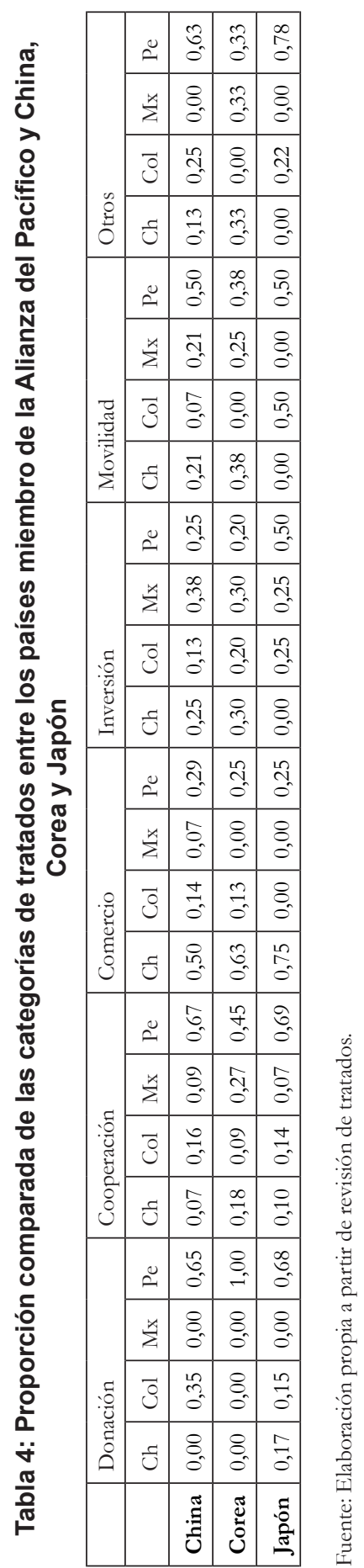




\section{Comentario final: la diversidad temática como fundamento de las relaciones entre los miembros de la Alianza del Pacífico y China, Corea y Japón}

Este texto se enmarca en la importancia coyuntural que tiene el Pacífico global y las expectativas ambientadas en el mismo para los países que hacen parte de la cuenca. Para los Estados miembro de la Alianza del Pacífico es una apuesta central reforzar su posicionamiento en la misma, sobre todo para Colombia, único socio con una inserción reciente.

Al respecto de esta última preocupación, uno de los principales hallazgos es que la literatura que analiza la inserción de estos cuatro países latinoamericanos a Asia-Pacífico ha tenido un marcado enfoque económico y comercial. Este, si bien es valioso, constituye un sesgo dentro de la literatura académica referida al tema, pues se ha dejado de lado el estudio de otras formas de relacionamiento externo que incluyen dimensiones igualmente importantes.

Este trabajo buscó cerrar esta brecha de conocimiento mediante el análisis de los tratados bilaterales entre los Estados miembro de la AP y China, Corea y Japón. Para realizar lo anterior se levantaron y sistematizaron los tratados bilaterales celebrados entre 1990 y 2016, construyendo así una base de datos —en la lógica de data minig-, que es entonces una contribución pionero en su clase y deja un precedente para posteriores análisis relacionados. Además, es insumo útil para futuros estudios y para la toma de decisiones por la calidad y diversidad de información en ella contenida.

El análisis realizado a partir de la base de datos permitió contrastar las relaciones que los miembros de la AP tienen con las contrapartes asiáticas. Al respecto se evidenció que el tema de comercio tiene una participación muy baja en la totalidad de las relaciones que se consolidan a través de los tratados, esta es del $9 \%$ frente al $91 \%$ de los tratados que tratan temas no comerciales. Si a la primera categoría se le suman los tratados de la categoría de inversión, temas estrechamente 
relacionados, su significancia sigue siendo muy baja: $15 \%$ frente al $85 \%$ de tratados no comerciales ni de inversión.

En relación con la categoría comercial, se pudo observar que Colombia no tiene suficientemente desarrolladas las herramientas jurídicas que permitan dinamizar sus relaciones comerciales con las contrapartes asiáticas, en cambio Chile y Perú tienen una posición privilegiada en ese sentido, seguidos de México, a pesar de la importancia de su relación con Estados Unidos en términos económicos.

Asimismo se pudo identificar la relevancia cardinal de las donaciones. Los tratados de esta categoría representan casi la mitad del total (47\%) y son constantes a través del tiempo. Es necesario resaltar que estas donaciones se dan en un solo sentido, es decir, son los países asiáticos los que donan el dinero a los latinoamericanos. No existe un solo tratado que se aleje de ese patrón y los únicos receptores son Colombia y Perú (35 \% y 65 \% respectivamente). De igual forma, Perú concentra casi tres cuartas partes $(67 \%)$ de los tratados referidos a cooperación, seguido muy atrás por Colombia (19\%). El primer país también tiene la mayor proporción de tratados de movilidad (50 \%), donde Chile y México se encuentran en segundo lugar (21\%) e, igual que antes, Colombia esta relegado en el cuarto puesto $(7 \%)$.

La anterior descripción general de los resultados conlleva implícitamente un análisis del estado de las relaciones con las contrapartes asiáticas con las que cada uno de los países latinoamericanos llega a conformar el proyecto de integración. Por ello es relevante la identificación de la variedad de temas en la medida en que la inserción también pasa por estos. La caracterización realizada puede servir como un indicador más de la inserción de los países miembros de la AP en Asia-Pacífico, que contiene, pero va más allá, de las relaciones comerciales. 


\section{Referencias}

Alianza del Pacífico. (2011). Declaración de Mérida de la II Cumbre de la Alianza del Pacífico. Mérida: México. Recuperado el 2 de mayo de 2016 de http://chile.gob.cl/mexico/files/2011/06/ANEXO-5declaracion-de-merida.pdf

Alianza del Pacífico. (2012). Acuerdo Marco de la Alianza del Pacifico. Paranal: Alianza del Pacífico.

Alianza del Pacífico. (2016). alianzapacifico.net. Recuperado el 3 de abril de 2016, de https:/ /alianzapacifico.net/que-es-la-alianza/

Alzate, E. U. (2002). El Tribunal Constitucional en México: perspectivas y posibilidad. En Vega Gómez, J. y Corzo Sosa, E. (Eds.). Tribunales de justicia constitucional. Memorias del VII Congreso Iberoamericano de Derecho Constitucional. México, D. F.:, Instituto de Investigaciones Jurídicas, pp. 537-548.

Aminian, N., Fung, K. C. \& Ng, F. (2009). A Comparative Analysis of Trade and Economic Integration in East Asia and Latin America, en Economic Change and Restructuring, (42), 105-137.

Artaza, M. (2007). Chile y Asia hoy: una mirada crítica. Estudios Internacionales (156), 55-65.

Aust, A. (2010). Handbook of International Law. Cambridge: Cambridge University Press.

Banco Interamericano de Desarrollo (BID). (2016). Nuevas tendencias en los tratados comerciales en América Latina. Washington, D. C.: Banco Interamericano de Desarrollo.

Barbosa, F., Posada, E. \& Serrano, E. (2011). La inserción de Colombia en el Asia Pacífico 2020: Colombia en el nuevo océano. Bogotá: Ministerio de Relaciones Exteriores; Universidad de Bogotá Jorge Tadeo Lozano.

Bazán, V. (2003). Jurisdicción constitucional, control de constitucionalidad de los tratados y convenios internacionales, y reforma de la Ley Fundamental. Pensamiento Constitucional, IX, (9), 413-462.

Bonilla, R. (2011). Apertura y reprimarización de la economía colombiana. Un paraíso de corto plazo. Nueva Sociedad, (231), 46-65.

Bhagwati, J. (1995). US Trade Policy: The infatuation with FTAs. New York: Columbia University.

Briceño, J. (2013). Ejes y modelos en la etapa actual de la integración económica regional en América Latina. Estudios Internacionales, (175), 9-39. 
Calderón, L. (2016). Colombia y la importancia de pertenecer al Foro de Cooperación Económica Asia-Pacífico. In Crescendo. Institucional 7 (2), $130-135$.

Cassese, A. (2005). International Law. Oxford: Oxford University Press.

Conforti, B. (2001). Notes on the Relationship Between International Law and National Law. En International Law Association (Ed.), International Law FORUM du droit international. The Hague: Kluwer Law International, pp. 18-24.

Constitución Política de Chile de 2005. Recuperado el 3 de abril de 2016, de https://www.leychile.cl/Navegar?idNorma=242302

Constitución Política de Colombia de 1991. Recuperado el 3 de abril de 2016, de https://www.ramajudicial.gov.co/documents/10228/1547471/ CONSTITUCION-Interiores.pdf/8b580886-d987-4668-a7a8$53 \mathrm{f0} 26 \mathrm{fOf3a2}$

Constitución Política de los Estados Unidos Mexicanos. Recuperado el 3 de abril de 2016, de http:/ /www.diputados.gob.mx/LeyesBiblio/ $\mathrm{htm} / 1 . \mathrm{htm}$

Constitución Política de Perú de 1993. Recuperado el 3 de abril de 2016, de http://www4.congreso.gob.pe/ntley/Imagenes/Constitu/Cons1993. pdf

Convención de Viena sobre el Derecho de los Tratados de 23 de Mayo de 1969. Viena: Comisión de Derecho Internacional de las Naciones Unidas.

Coutin, R. \& Terán, J. (2016). La Alianza del Pacífico: ¿apuesta estratégica de la política exterior colombiana? Estudios Gerenciales, (32), 346-357.

Clinton, H. (2011). America's Pacific Century. Recuperado el 3 de abril de 2016, de http:// foreignpolicy.com/2011/10/11/americas-pacificcentury/

Diario Financiero (2016). China y Chile firman 12 acuerdos de cooperación y elevan relaciones a categoría de "asociación estratégica integral". Recuperado el 22 de noviembre de 2016, de https:/ / www.df.cl/noticias / internacional/actualidad-internacional/china-y-chile-firman-12-acuerdos-de-cooperacion-y-elevan-relaciones-a/2016-11-22/192632.html

Ding, S. (2008). To Build a "Harmonious World": China's Soft Power Wieldind in the Global South. Journal of Chinese Political Science, 13 (2, 8), 193-213. 
Easton, D. (1957). An Approach to the Analysis of Political Systems. World Politics, 9 (3), 383-400.

Excelsior (2016). Suscriben acuerdos bilaterales México y Corea del Sur. Recuperado el 4 de abril de 2016, de http:/ / www.excelsior.com.mx/ nacional/2016/04/04/1084472

Faust, J. \& Franke, U. (2002). Attempts at Diversification: Mexico and Pacific Asia. Pacific Review, 15 (2), 299-324.

Faust, J. (2004). Latin America, Chile and East Asia: Policy-Networks and Successful Diversification. Journal of Latin American Studies (36), 743770 .

Fernández de Soto, G. \& Pineda, S. (2012). El Pacifico: la inserción aplaz̧ada. La relación de Colombia con el Asia-Pacifico en el contexto de América Latina. Bogotá: Panamericana Formas e Impresos S. A.

Ferrero D. A. (2014). APEC y Perú: estableciendo nuevos vínculos con Asia Pacífico. Apuntes: Revista De Ciencias Sociales, 0 (46), 77-100.

Forero, F. (2015). Diversificación y autonomía en la política exterior latinoamericana. Desafios, 27 (II), 291-322.

Gago, C. (2001). Relaciones del MERCOSUR y del Pacto Andino con los países de la APEC del Pacífico Occidental. Espacio y Desarrollo, (13), 107-138.

Godoy, V. (2016). La Alianza del Pacífico: ¿Hacia el camino de la integración? Relaciones Internacionales, (89.1), 77-93.

Gómez, L. (2009). Metodología y técnicas en el Derecho Comparado. Temas Socio-Jurídicos, 27, (57), 33-67.

González, C., Mesa, J. \& Londoño, G. (2016). Política exterior colombiana 2010-2014: ¿Giro a la autonomía? Revista de Relaciones Internacionales, Estrategia y Seguridad, 12 (1), 267-291.

Guerra, A. (2014). Una aproximación “inside-out” a la política exterior económica peruana. En Pastrana, E. y Gehring, H. (Eds.). Alianza del Pacifico: mitos y realidades. Cali: Editorial Universidad Santiago de Cali, pp. 223-249.

Irigoitia, G. (2014). Los procesos de integración regional y su abordaje desde una visión más comercial y técnica. Revista de la Secretaría del Tribunal Permanente de Revision, 2, (3), 219-235.

Jugurnath, B., Stewart, M. \& Brooks, R. (2007). Asia/Pacific Regional Trade Agreements: An empirical study. Journal of Asian Economics (18), 974-987. 
La República (2016). Perú y China firman convenio de cooperación para proteger el medio ambiente. Recuperado el 21 de noviembre de 2016, de http://larepublica.pe/politica/823751-peru-y-china-firman-conveniode-cooperacion-para-proteger-el-medio-ambiente

León-Manríquez, J. \& Tzili Apango, E. (2015). México y Asia Pacífico: proximidades y distancias de una dilatada relación. Revista CIDOB d'Afers Internacionals, (110), 113-139.

Menéndez, F. M. (2005). Derecho internacional público. Parte general. Madrid: Trotta.

Milanese, J. P. (2007). Colombia y Venezuela. Interpresidencialismo e integración regional. Cali: Universidad Icesi.

Milanese, J. \& Fernández, J. (2012). La política exterior colombiana a la luz de los tratados ratificados por el Congreso entre 1968 y 2011. En Jost, E. (Ed.). ¿Colombia una potencia en desarrollo? Escenarios y desafíos para su política exterior. Bogotá: Fundación Konrad Adenauer, pp. 409-428.

Monroy, M. G. (2008). El Derecho Internacional como fuente del Derecho Constitucional. Anuario Colombiano de Derecho Internacional - ACDI, 1 (1), 107-138.

Observatorio América Latina-Asia Pacífico. (s.f.). observatorioasiapacifico. org. Recuperado el 14 de mayo de 2016, de http://www.observatorioasiapacifico.com/data/OBSERVATORIO.Images/Bulletin/ temp/20151117121525BoletnAL-AsiaNmero07.pdf

Pastrana, E., Betancourt, R. \& Castro, R. (2014). Colombia y la Alianza del Pacífico: un proyecto regional de cara a la multipolaridad creciente. En Pastrana, E. y Gehring, H. (Eds.). Alianza del Pacifico: mitos y realidades. Cali: Editorial Universidad Santiago de Cali, pp. 173-205.

Prieto, G. \& Ladino, N. (2014). La proyección de Chile en Asia-Pacífico. En Pastrana, E. y Gehring, H. (Eds.). Alianza del Pacifico: mitos y realidades. Cali: Editorial Universidad Santiago de Cali, pp. 251-291.

Ramírez, G. (1999). Política exterior y tratados públicos. Bogotá: Universidad Externado de Colombia.

Rodríguez, I. (2014). Nuevas configuraciones económicas en el Asia-Pacífico y sus consecuencias para América Latina: Desde el APEC a la Alianza del Pacífico. Dados - Revista de Ciências Sociais, 57 (2), 553-580. 
Romero, M. \& Rivera, O. (2013). Los retos actuales de la política exterior mexicana: una revisión desde la geopolítica crítica. Asian Journal of Latin American Studies, 26 (3), 1-28.

Ross, C. (2007). Chile y el Asia Pacífico: la construcción histórica del futuro. Si Somos Americanos. Revista de Estudios Transfronterizos, IX (1), 109-140.

Sanhueza, R. \& Soto, A. (2009). Chile en el contexto del Pacífico. Marcos conceptuales para la política exterior de Chile hacia el Asia Pacífico. UNISCI Discussion Papers (21), 120-136.

Scott, S. V. (2005). Identifying the Source and Nature of State's Political Obligation towards International Law. Journal of International Law \& International Relations, 1 (1-2), 49-60.

Slaughter, A. M., Tulumello, A. \& Wood, S. (1998). International Law and International Relations Theory: A New Generation of Interdisciplinary Scholarship. The American Journal of International Law, 92 (3), 367-397.

Stimmer, G. (2013). Las estrategias de integración de América Latina y Europa en el espacio Asia-Pacífico entre competencia y cooperación, en Aldea Mundo 18 (36), 81-89.

Sweigert, K. (2002). Introducción al Derecho Comparado. México: Oxford University Press.

Terán, J. M. (2016). www.icesi.edu.co/peap. Recuperado el 2 de mayo de 2016, de http://us11.campaign-archive1.com/?u=5297ba32528913 0bca32f4047\&id=8d5dc23909

Torres, P. R. (2011). La utilización del método comparado en los procesos de Reforma y de implementación de los Sistemas de Justicia Penal con especial referencia a México. Archivio Penale, (2), 1-22.

Torres, J. (2013). Colombia: inserción y desequilibrios comerciales en la Cuenca del Pacífico. Revista Problemas de Desarrollo, 174 (44), 139-165.

Trejo, E. D. (2006). Los tratados internacionales como fuente de derecho nacional. México, D. F.: Servicio de Investigación y Analisis de la Cámara de Diputados.

Tremolada, E. (2014). ¿La Alianza del Pacífico facilita la inserción de Colombia en la región Asia-Pacífico? Papel Político, 19 (2), 721-752.

UNAM. (16 de agosto de 2011). Sistemas Juridicos UNAM. Recuperado el 3 de abril de 2016 de https: / sistemasjuridicosunam.wordpress.com/ Van Laer, C. (1998). The Applicability of Comparative Concepts. Electronic Journal Of Comparative Law, 2.2. Recuperado el 3 de abril de 2016 de http://www.ejcl.org/22/art22-1.html 
Vargas, O. (2009). Los tratados y la Constitución nacional. Revista Debate, VII (16), 89-118.

Veltmeyer, H. (2012). The Natural Resource Dynamics of Postneoliberalism in Latin America: New Developmentalism or Extractivist Imperialism? Studies in Political Economy, 90 (1), 57-85.

Wise, C. (2016). Playing Both Sides of the Pacific: Latin America's Free Trade Agreement with China. Pacific Affairs, 89 (1), 75-101. 